\title{
PEMANFAATAN PELEPAH KELAPA SAWIT (Elaeis guineensis) DENGAN PENAMBAHAN PATI KULIT SINGKONG (Manihot utilissima) DALAM PEMBUATAN BRIKET

\author{
Utilization of Palm Oil Palace (Elaeis guineensis) With Additional of Cassava Starch
} (Manihot utilissima) In Manufacture of Bricket
}

\author{
Desi Ardilla ${ }^{1}$, Misril Fuadi ${ }^{1}$ dan Azzy Hasby Prasetio ${ }^{1}$ \\ 1Fakultas Pertanian Universitas Muhammadiyah Sumatera Utara \\ desiardilla@umsu.ac.id
}

\begin{abstract}
Palm briquette briquette production as one of the fuel substitutes that began to thin and as a source of renewable alternative energy is done with the addition of cassava starch. This research used Factorial Randomized Complete Design (RAL) with two replications. Factor I is the addition of cassava husk starch with a password (P) consisting of 4 levels, namely: $\mathrm{P}_{1}=5 \%, \mathrm{P}_{2}=10 \%, \mathrm{P}_{3}=15 \%, \mathrm{P}_{4}=20 \%$. Factor II is the drying temperature with the code (S) consisting of 4 levels, namely: $\mathrm{S}_{1}=100^{\circ} \mathrm{C}, \mathrm{S}_{2}=$ $110^{\circ} \mathrm{C}, \mathrm{S}_{3}=120^{\circ} \mathrm{C}, \mathrm{S}_{4}=130^{\circ} \mathrm{C}$. Parameters observed included heating value, moisture content, ash content. Statistical analysis result on each parameter show: The addition of Cassava Starch has a very significant different effect $(\mathrm{P}<0.01)$ on the calorific value. The addition of Cassava Starch gave a very significant different effect $(\mathrm{P}<0.01)$ on Briket Water Content. The addition of Cassava Starch gave a very significant different effect $(\mathrm{P}<0.01)$ on Ash Content in Briquette.
\end{abstract}

Keywords : Cassava leaf, palm stem, briquettes, calorific value

\section{A. PENDAHULUAN}

Energi merupakan permasalahan utama dunia saat ini. Tiap tahunnya kebutuhan akan energi semakin meningkat seiring dengan semakin meningkatnya aktivitas manusia yang menggunakan bahan bakar terutama bahan bakar minyak yang di peroleh dari fosil tumbuhan maupun hewan. Ketersediaan bahan bakar fosil yang semakin langka berakibat pada kenaikan harga bbm, oleh karena itu diperlukan suatu terobosan bahwa energy alternatif dapat mengurangi penggunaan bahan bakar minyak. Salah satu energy alternatif tersebut adalah memanfaatkan pelepah kelapa sawit sebagai energi biomassa.

Penelitian terdahulu telah menggunakan sekam padi,ampas tebu sebagai zat aditif untuk meningkatkan nilai kalor pada pembuatan briket cangkang sawit (Ardilla, dkk. 2011). Briket merupakan gumpalan arang yang terbuat dari bahan lunak yang dikeraskan. Faktorfaktor yang mempengaruhi sifat briket arang adalah berat jenis bahan atau berat jenis serbuk arang, kehalusan serbuk, suhu karbonisasi, tekanan pengempaan, dan pencampuran formula bahan baku briket. Proses pembriketan adalah proses pengolahan yang mengalami perlakuan penumbukan, pencampuran bahan baku, pencetakan dengan sistem hidrolik dan pengeringan pada kondisi tertentu, sehingga diperoleh briket yang mempunyai bentuk, ukuran fisik, dan sifat kimia tertentu. Proses pembuatan karbon aktif dan briket arang cangkang sawit telah dilakukan oleh peneliti (Ardilla dkk, 2011). Pembriketan bertujuan untuk memperoleh suatu bahan bakar yang berkualitas yang dapat digunakan untuk semua sektor sebagai sumber energi alternative ysng terbarukan karbon aktif berbahan baku cangkang kelapa sawit yang juga berorientasi tentang ketersediaan sumber energy alternative telah dilakukan peneliti (Ardilla, dkk, 2007).

Pemanfaatan pelepah kelapa sawit selama ini belum optimal pada beberapa penelitan sebelumnya pelepah kelapa sawit di gunakan sebagai bahan fermentasi dengan Aspergillus niger untuk pertambahan bobot badan sapi (Pahala T. G. Situmorang, 2010), penggunaan pelepah kelapa sawit fermentasi dengan berbagai level biomol pada pakan terhadap 
karkas domba lokal jantan (Husin Ahmad, 2014), Variasi komposisi dan sumber nutrisi bagi miselium pada proses pelapukan pelepah kelapa sawit untuk mendegradasi lignin dengan pleurotus ostreatus (Nadia, 2012), Pengaruh asam sitrat, suhu, dan waktu pengempaan terhadap sifat papan pertikel dari pelepah kelapa sawit (Kurnia, 2013), Serat pelepah kelapa sawit untuk bahan baku produk kerajinan (Retno, 2015). Berdasarkan penelitian terdahulu pelepah kelapa sawit poten untuk dijaikan sebagai bahan baku energy alternative dalam bentuk produk briket. Kulit singkong sering kali dianggap limbah yang tidak berguna oleh sebagian industri berbahan baku singkong. Oleh karena itu, bahan ini masih belum banyak dimanfaatkan dan dibuang begitu saja dan umumnya hanya digunakan sebagai pakan ternak. Untuk pengolahan limbah singkong selama ini biasanya dimanfaatkan sebagai kompos, makan ternak, dan sebagai bioenergi.

\section{B. METODOLOGI \\ Bahan dan Alat}

Bahan penelitian yang digunakan adalah Pelepah kelapa sawit, Pati Kulit singkong sebagai perekat, air.

Adapun alat penelitian yang di gunakan adalah sebagai berikut : Oven, ayakan 20 mesh, lumpang atau alu, cetakan briket, blender, kompor, tungku pembakaran, batang pengaduk, timbangan analitik, ember dan baskom.

\section{Metode Penelitian}

Metode penelitian dilakukan dengan metode Rancangan Acak Lengkap (RAL) faktorial yang terdiri dari 2 faktor yaitu:

Faktor I : Penambahan pati kulit singkong (P) yang terdiri dari 4 taraf

$$
\begin{aligned}
& \mathrm{P}_{1}=5 \% \\
& \mathrm{P}_{2}=10 \% \\
& \mathrm{P}_{3}=15 \% \\
& \mathrm{P}_{4}=20 \%
\end{aligned}
$$

Faktor II : Suhu pengeringan (S) yang terdiri dari 4 taraf

$$
\begin{aligned}
& S_{1}=100^{\circ} \mathrm{C} \\
& S_{2}=110^{\circ} \mathrm{C} \\
& S_{3}=120^{\circ} \mathrm{C} \\
& S_{4}=130^{\circ} \mathrm{C}
\end{aligned}
$$

Banyaknya kombinasi perlakuan (Tc) adalah $4 \times$ $4=16$, dengan jumlah ulangan (n) adalah sebagai berikut:

$$
\text { Tc }(n-1) \geq 15
$$

\author{
$16(\mathrm{n}-1) \geq 15$ \\ $16 n-16 \geq 15$ \\ $16 \mathrm{n} \geq 31$ \\ $\mathrm{n} \geq 1,94$ (dibulatkan menjadi 2 ulangan)
}

\section{Model Rancangan Percobaan}

Penelitian ini dilakukan dengan Rancangan

Acak Lengkap (RAL) faktorial dengan model :

Dimana :

$$
\text { Yijk }=\mu+\alpha i+\beta j+(\alpha \beta) i j+\varepsilon i j k
$$

Yijk : Pengamatan dari factor P dari taraf ke-I dan faktor $S$ pada taraf ke- dengan ulangan ke-k.

$\mu \quad$ : Efek nilai tengah

$\alpha \mathrm{i} \quad$ : Efek dari faktor P pada taraf ke-i.

$\beta \mathrm{j} \quad$ : Efek dari faktor $S$ pada taraf ke-j.

$(\alpha \beta)$ ij: Efek interaksi faktor P pada taraf ke-I dan faktor pada taraf ke-j.

Eijk : Efek galat dari faktor P pada taraf ke-I dan faktor $S$ pada taraf ke-j dalam ulangan ke-k.

\section{Pelaksanaan Penelitian}

\section{Pembuatan Pati Kulit Singkong}

1. Sediakan kulit singkong

2. Kemudian sortasi kulit singkong dan pisah kulit luar kulit singkong agar kulit singkong benar benar bersih.

3. Lalu haluskan kulit singkong dengan menggunakan dengan blender supaya lebih halus.

4. Kemudian campur kulit singkong yang sudah di haluskan dengan air dan di peras menggunakan kain kasa.

5. Kemudian diamkan hasil perasan kulit singkong selama 1 malam agar mendapat pati kulit singkong.

6. Kemudian pisahkan air dengan endapan pati kulit singkong

7. Kemudian oven pati kulit singkong

\section{Pembuatan Briket Pelepah Kelapa Sawit}

1. Sediakan pelepah kelapa sawit.

2. Kemudian sortasi pelepah sawit yang sudah kering agar proses pembakaran lebih mudah dan mendapatkan karbon.

3. Lalu tumbuk pelepah sawit yang sudah di bakar dengan menggunakan alu agar proses pengayakan lebih mudah.

4. Kemudian di ayak menggunakan ayakan 20 mesh.

5. Setelah itu campurkan dengan perekat dari pati kulit singkong agar pelepah yang sudah di haluskan mudah di cetak. 
6. Kemudian cetak dengan menggunakan cetakan briket agar bentuknya lebih menarik.

7. Lalu di pres agar hasil briket padat.

8. Kemudian di oven selama 3 jam agar briket benar benar kering.

9. Kemudian kemas.

\section{Parameter Pengamatan}

Pengamatan dilakukan berdasarkan analisa yang meliputi :

A. Uji Nilai Kalor (Apriyantono, 1989).

Nilai kalor HHV $(\mathrm{cal} / \mathrm{g})=\frac{[(\Delta \mathrm{t}) \mathrm{EEEV}]-(\mathrm{e} 1+\mathrm{e} 2)}{n} x \mathrm{Es}$ Dimana

$\Delta \mathrm{t}$ : Adalah kenaikan suhu pembakaran didalam bom kalorimeter $\left({ }^{0} \mathrm{c}\right)$

EEV adalah energi ekivalen saat terjadi pembakaran cal $/{ }^{\circ} \mathrm{C}$ )

$\mathrm{e}_{1}$ adalah koreksi panas karena pembentukan asam (cal)

$\mathrm{e}_{2}$ adalah koreksi panas pembakaran dari kawat pembakar (cal)

es adalah koreksi sulfur yang ada dalam bahan bakar (cal/g)

$\mathrm{m}$ adalah berat contoh $(\mathrm{g})$

\section{B. Kadar Air (Sudarmaji dkk, 1996).}

Kadar air ditentukan dengan cara contoh ditimbang sebanyak 5 gram kemudian dikeringkan pada oven pada suhu $150{ }^{\circ} \mathrm{C}$ selama 4 jam. Setelah itu didinginkan dalam desikator selama 5 menit lalu di timbang. Perlakuan ini diulang sampai mencapai berat konstan. Kadar air dapat dihitung dengan rumus:

$$
\mathrm{KA}=\frac{\text { Berat Awal-Berat Akhir }}{\text { Berat Awal }} \times 100 \%
$$

\section{Kadar Abu (Apriyantono, 1989)}

Penentuan kadar abu menggunakan metode pengabuan kering. Cawan yang telah dibersihkan dipanaskan dalam tanur pada suhu $100^{\circ} \mathrm{C}$ selama 2 jam lalu ditimbang sebagai bobot kosong. Contoh yang telah diuapkan ditimbang teliti \pm 1 gram dalam cawan dan dinyatakan sebagai bobot awal, kemudian cawan tersebut dimasukkan ke dalam tanur suhu $600^{\circ} \mathrm{C}$ selama 5 jam. Setelah pemanasan cawan dimasukkan ke dalam desikator, dan setelah dingin ditimbang sampai diperoleh bobot tetap sebagai bobot akhir.

$$
\text { Kadar Abu }=\frac{\text { Berat Abu }}{\text { Berat Sampel }} \times 100 \%
$$

\section{HASIL DAN PEMBAHASAN}

Dari hasil penelitian dan uji statistik, secara umum menunjukkan bahwa konsentrasi penambahan jumlah Pati Kulit Singkong berpengaruh terhadap parameter yang diamati. Data rata-rata hasil pengamatan pengaruh konsentrasi penambahan jumlah Pati Kulit Singkong terhadap masing-masing parameter dapat dilihat pada tabel 1 .

Tabel 1. Pengaruh Penambahan Pati Kulit Singkong Terhadap Parameter Yang Diamati

Penambahan

Pati Kulit Nilai kalor Kadar Air Kadar Abu

Singkong $\quad(\mathrm{kal} / \mathrm{g}) \quad(\%) \quad(\%)$

\begin{tabular}{|c|c|c|c|}
\hline $\mathrm{P}_{1}=5 \%$ & 5389.809 & 21.669 & 19.293 \\
\hline$P_{2}=10 \%$ & 5055.801 & 22.550 & 14.471 \\
\hline$P_{3}=15 \%$ & 4855.906 & 23.425 & 10.675 \\
\hline$P_{4}=20 \%$ & 4676.338 & 24.906 & 7.018 \\
\hline
\end{tabular}

$(\%)$ penambahan jumlah pati kulit singkong terhadap nilai kalor dan kadar abu semakin menurun, sedangkan kadar air semakin meningkat. Suhu Pengeringan setelah diuji secara statistik, memberi pengaruh yang berbeda terhadap parameter yang diamati. Data rata-rata hasil pengamatan disajikan pada tabel 2.

Tabel 2. Pengaruh Suhu Pengeringan terhadap Parameter yang Diamati

\begin{tabular}{cccc}
\hline $\begin{array}{c}\text { Suhu } \\
\text { Pengeringan } \\
\left({ }^{\circ} \mathrm{C}\right)\end{array}$ & $\begin{array}{c}\text { Nilai Kalor } \\
(\mathrm{kal} / \mathrm{g})\end{array}$ & $\begin{array}{c}\text { Kadar Air } \\
(\%)\end{array}$ & $\begin{array}{c}\text { Kadar Abu } \\
(\%)\end{array}$ \\
\hline $\mathrm{S}_{1}=100^{\circ} \mathrm{C}$ & 4605.661 & 26.075 & 14.688 \\
$\mathrm{~S}_{2}=110^{\circ} \mathrm{C}$ & 4891.691 & 24.844 & 13.123 \\
$\mathrm{~S}_{3}=120^{\circ} \mathrm{C}$ & 5143.061 & 22.450 & 12.144 \\
$\mathrm{~S}_{4}=130^{\circ} \mathrm{C}$ & 5257.440 & 19.181 & 11.503 \\
\hline
\end{tabular}

Dari Tabel 2. Dapat dilihat bahwa semakin tinggi Suhu Pengeringan maka Nilai Kalor semakin meningkat, sedangkan Kadar Air dan Kadar Abu semakin menurun.

\section{Nilai Kalor}

\section{Pengaruh Penambahan Pati Kulit Singkong Terhadap Nilai Kalor}

Dari daftar sidik ragam (Lampiran 1) dapat di lihat bahwa Penambahan Pati Kulit Singkong berpengaruh berbeda sangat nyata $(\mathrm{P}$ $<0,01)$ terhadap Nilai Kalor. Tingkat perbedaan tersebut telah diuji dengan uji beda rata-rata dapat di lihat pada tabel 3 . 
Tabel 3. Hasil Uji Beda Rata-Rata Pengaruh Penambahan Pati Kulit Singkong Terhadap Nilai Kalor

\begin{tabular}{|c|c|c|c|c|c|c|}
\hline \multirow{2}{*}{$\begin{array}{c}\text { Penambahan } \\
\text { Pati Kulit } \\
\text { Singkong (P) } \\
\end{array}$} & \multirow[b]{2}{*}{ Rataan } & \multirow[b]{2}{*}{ Jarak } & \multicolumn{2}{|c|}{ LSR } & \multicolumn{2}{|c|}{ Notasi } \\
\hline & & & 0,05 & 0,01 & 0,05 & 0,0 \\
\hline $\mathrm{P}_{1}=5 \%$ & 5389.809 & - & - & - & $\mathrm{a}$ & $\mathrm{A}$ \\
\hline$P_{2}=10 \%$ & 5055.801 & 2 & 41.430 & 57.035 & b & B \\
\hline$P_{3}=15 \%$ & 4855.906 & 3 & 43.501 & 59.935 & c & $\mathrm{C}$ \\
\hline $\mathrm{P}_{4}=20 \%$ & 4676.338 & 4 & 44.606 & 61.454 & d & D \\
\hline
\end{tabular}

Dari tabel 3. Dapat dilihat bahwa $\mathrm{P}_{1}$ berbeda sangat nyata dengan $\mathrm{P}_{2}, \mathrm{P}_{3}$ dan $\mathrm{P}_{4} \mathrm{P}_{2}$ berbeda sangat nyata dengan $\mathrm{P}_{3}$ dan $\mathrm{P}_{4} . \mathrm{P}_{3}$ berbeda sangat nyata dengan $\mathrm{P}_{4}$. Nilai Kalor tertinggi terdapat pada perlakuan $\mathrm{P}_{1}$ yaitu sebesar $5389.809 \mathrm{kal} / \mathrm{g}$, dan terendah terdapat pada perlakuan $\mathrm{P}_{4}$ yaitu sebesar $4676.338 \mathrm{kal} / \mathrm{g}$. Untuk lebih jelas nya dapat di lihat pada gambar 1

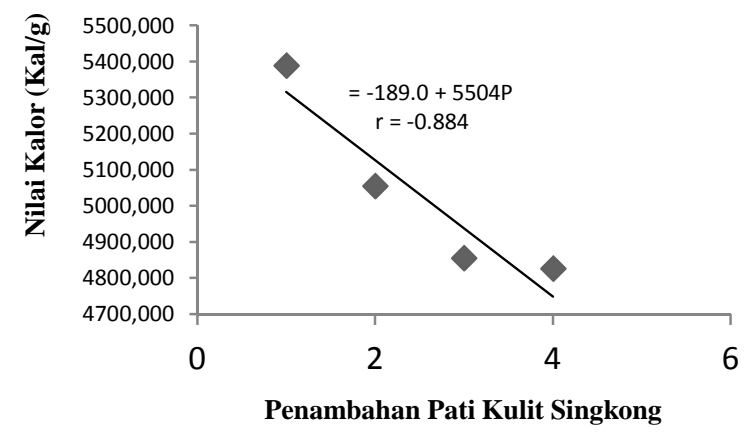

Gambar 1: Hubungan Penambahan Pati Kulit Singkong Terhadap Nilai Kalor

Dari Gambar 1. Dapat dilihat bahwa penambahan jumlah pati kulit singkong terhadap nilai kalor. Semakin banyak pati kulit singkong yang ditambahkan maka nilai kalor semakin menurun yaitu $4676.338 \mathrm{kal} / \mathrm{g}$. Berdasarkan penelitian yang telah dilakukan sebelumnya oleh Manik (2010). Penambahan bahan limbah pertanian akan meningkatkan nilai kalor, hal ini sesuai dengan Pancapalaga (2008) yang menyatakan bahwa limbah pertanian dapat menghasilkan energi kalor sekitar $6000 \mathrm{kal} / \mathrm{g}$. jadi semakin banyak limbah limbah pertanian dalam pencampuran pembuatan briket akan menghasilkan nilai kalor.

\section{Pengaruh Suhu Pengeringan Terhadap Nilai Kalor}

Dari sidik ragam (Lampiran 1) dapat dilihat bahwa Suhu Pengeringan berpengaruh berbeda sangat nyata $(\mathrm{P}<0,01)$ terhadap Nilai Kalor. Tingkat perbedaan tersebut telah diuji dengan uji beda rata-rata dapat di lihat pada tabel 4 .

Tabel 4. Hasil Uji Beda Rata-Rata Suhu Pengeringan Terhadap Nilai Kalor

\begin{tabular}{lcccccc}
\hline \multirow{2}{*}{$\begin{array}{l}\text { Perlakuan } \\
(\mathrm{S})\end{array}$} & \multirow{2}{*}{ Rataan Jarak } & \multicolumn{2}{c}{ LSR } & \multicolumn{2}{c}{ Notasi } \\
\cline { 3 - 7 } & & 0,05 & 0,01 & 0,05 & 0,01 \\
\hline $\mathrm{S}_{1}=100^{\circ} \mathrm{C}$ & 4605.661 & - & - & - & $\mathrm{d}$ & $\mathrm{D}$ \\
$\mathrm{S}_{2}=110^{\circ} \mathrm{C}$ & 4891.691 & 2 & 41.430 & 57.035 & $\mathrm{C}$ & $\mathrm{C}$ \\
$\mathrm{S}_{3}=120^{\circ} \mathrm{C}$ & 5143.061 & 3 & 43.501 & 59.935 & $\mathrm{~b}$ & $\mathrm{~B}$ \\
$\mathrm{~S}_{4}=130^{\circ} \mathrm{C}$ & 5257.440 & 4 & 44.606 & 61.454 & $\mathrm{a}$ & $\mathrm{A}$ \\
\hline Keterangan: Huruf yang & berbeda & pada & kolom & notasi \\
menunjukkan pengaruh yang berbeda nyata pada taraf $5 \%$ \\
dan berbeda sangat nyata pada taraf 1\%
\end{tabular}

Dari tabel 4. Dapat dilihat bahwa $S_{1}$ berbeda sangat nyata dengan $S_{2}, S_{3}, S_{4}$. $S_{2}$ berbeda sangat nyata dengan $\mathrm{S}_{3}$ dan $\mathrm{C}_{4}$. $\mathrm{C}_{3}$ berbeda sangat nyata dengan $\mathrm{C}_{4}$. Nilai Kalor tertinggi terdapat pada perlakuan $\mathrm{S}_{4}$ yaitu sebesar $5257.440 \mathrm{kal} / \mathrm{g}$, dan terendah terdapat pada perlakuan $\mathrm{S}_{1}$ yaitu sebesar $4605.661 \mathrm{kal} / \mathrm{g}$. Untuk lebih jelasnya dapat dilihat pada gambar 2 .

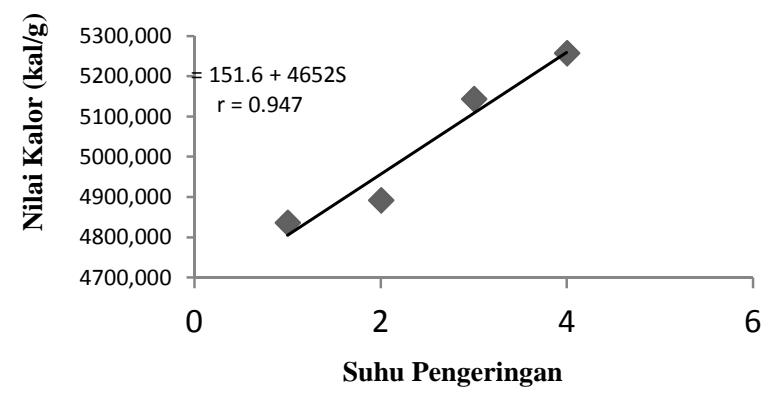

Dari Gambar 2. Dapat dilihat bahwa suhu pengeringan berpengaruh terhadap nilai kalor semakin tinggi suhu pengeringan maka nilai kalor semakin meningkat. Menurut (Purnama dkk, 2012). Semakin tinggi suhu pirolisis maka nilai kalor akan semakin tinggi hal ini dipengaruhi oleh tingginya kandungan karbon terikat pada briket arang, sebab didalam proses pembakaran membutuhkan karbon yang akan bereaksi dengan oksigen untuk menghasilkan kalor.

\section{Pengaruh Interaksi Antara Penambahan Pati Kulit Singkong dengan Suhu Pengeringan Terhadap Nilai Kalor}

Dari daftar anailisis sidik ragam diketahui bahwa interaksi penambahan pati kulit singkong dan suhu pengeringan memberikan pengaruh berbeda sangat nyata $(\mathrm{P}<0.01)$ terhadap nilai kalor. Hasil uji LSR pengaruh interaksi penambahan pati kulit singkong dan 
suhu pengeringan terhadap nilai kalor pada briket.

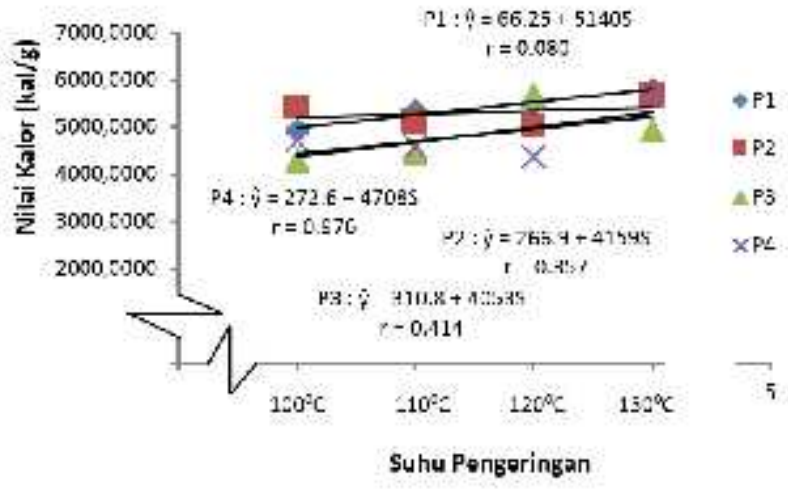

Gambar 3 : Grafik Hubungan Interaksi Penambahan Pati Kulit Singkong Dan Suhu Pengeringan Terhadap Nilai Kalor Briket

Dari gambar 3 terlihat bahwa semakin banyak jumlah perekaat $20 \%$ yang di campurkan dengan arang memiliki tektur seperti bubur pada saat proses pencampuran sehingga menimbulkan nilai kalor yang semakin rendah dan pada saat pencampuran perekat $5 \%$ memiliki tekstur yang lembab sehingga mempermudah proses pencetakan sehingga briket padat. Hal ini sependaapat dengan Tobing (2007) yang menyatakan bahwa semakin besar persentase jumlah pengikat pada briket, maka nilai kalor yang dihasilkan akan semakin rendah. Pada saat proses pengeringan dengan suhu $130{ }^{\circ} \mathrm{C}$ sehingga briket yang di hasilkan sangat kering dan padat dan meningkatkan nilai kalor tertingggi terlihat pada komposisi arang pelepah sawit dan pati kulit singkong 95\% + 5\% yaitu 5776.9200 $\mathrm{kal} / \mathrm{gr}$ pada suhu $130{ }^{\circ} \mathrm{C}$.

\section{Kadar Air \\ Pengaruh Penambahan Pati Kulit \\ Singkong Terhadap Kadar Air}

Dari daftar sidik ragam (lampiran 2) dapat dilihat bahwa penambahan jumlah Pati Kulit Singkong berpengaruh berbeda sangat nyata ( $\mathrm{P}$ $<0,01)$ terhadap Kadar Air. Tingkat perbedaan tersebut telah diuji dengan uji beda rata-rata dapat dilihat pada tabel 5 .

Tabel 5. Hasil Uji Beda Rata-Rata Pengaruh Penambahan Pati Kulit Singkong Terhadap Kadar Air

\begin{tabular}{|c|c|c|c|c|c|c|}
\hline \multirow{2}{*}{$\begin{array}{l}\text { Perlakuan } \\
\text { (P) }\end{array}$} & \multirow{2}{*}{\multicolumn{2}{|c|}{ Rataan Jarak }} & \multicolumn{2}{|c|}{ LSR } & \multicolumn{2}{|c|}{ Notasi } \\
\hline & & & 0,05 & 0,01 & 0,05 & 0,01 \\
\hline$P_{1}=5 \%$ & 21.669 & - & - & - & d & D \\
\hline $\mathrm{P}_{2}=10 \%$ & 22.550 & 2 & 0.179 & 0.243 & $\mathrm{c}$ & $\mathrm{C}$ \\
\hline $\mathrm{P}_{3}=15 \%$ & 23.425 & 3 & 0.185 & 0.255 & b & B \\
\hline $\mathrm{P}_{4}=20 \%$ & 24.906 & 4 & 0.190 & 0.262 & $\mathrm{a}$ & A \\
\hline
\end{tabular}

Dari Tabel 5. Dapat dilihat bahwa $P_{1}$ berbeda sangat nyata dengan $\mathrm{P}_{2}, \mathrm{P}_{3}$, dan $\mathrm{P}_{4} . \mathrm{P}_{2}$ berbeda sangat nyata dengan $\mathrm{P}_{3}$ dan $\mathrm{P}_{4} \cdot \mathrm{P}_{3}$ berbeda sangat nyata dengan $\mathrm{P}_{4}$. Kadar Air tertinggi terdapat pada perlakuan $\mathrm{P}_{4}$ yaitu sebesar $24.906 \%$, dan terendah terdapat pada perlakuan $\mathrm{P}_{1}$ yaitu sebesar $21.669 \%$. Untuk lebih jelasnya dapat dilihat pada gambar 4 .

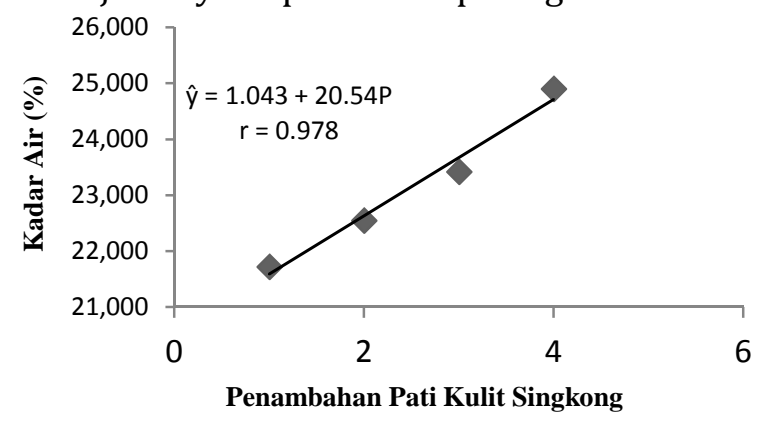

Gambar 4: Hubungan Penambahan Pati Kulit Singkong Terhadap Kadar Air

Dari gambar 4. Dapat dilihat bahwa pengaruh penambahan pati kulit singkong terhadap kadar air semakin meningkat. Kadar air briket berpengaruh terhadap nilai kalor. Nilai kalor akan semakin meningkat apabila semakin sedikit kadar air dalam briket, (Ardilla dkk, 2011). Seperti penelitian yang dilakukan oleh Gandhi (2010) yaitu semakin tinggi komposisi perekat maka nilai kalornya semakin rendah dan kadar air nya yang dihasilkan semakin tinggi pula, tetapi berat jenis dan kepadatan energi yang dihasilkan akan semakin rendah. Hal ini dikarenakan kandungan air yang terdapat dalam perekat sehingga apabila dicampur dengan arang akan berpengaruh terhadap nilai kadar air briket tersebut Purnama dkk (2012).

\section{Pengaruh Suhu Pengeringan Terhadap Kadar Air}

Dari daftar sidik ragam (lampiran 2) dapat di lihat bahwa Suhu Pengeringan berpengaruh berbeda sangat nyata $(\mathrm{P}<0,01)$ terhadap Kadar Air. Tingkat perbedaan tersebut telah diuji 
dengan uji beda rata-rata dapat di lihat pada tabel 6.

Tabel 6. Hasil Uji Beda Rata-Rata Suhu Pengeringan Terhadap Kadar Air

\begin{tabular}{lccccccc}
\hline \multirow{2}{*}{$\begin{array}{l}\text { Perlakuan } \\
\text { (S) }\end{array}$} & \multirow{2}{*}{ Rataan } & \multirow{2}{*}{ Jarak } & \multicolumn{2}{c}{ LSR } & \multicolumn{2}{c}{ Notasi } \\
\cline { 3 - 7 } & & & 0,05 & 0,01 & 0,05 & 0,01 \\
\hline $\mathrm{S}_{1}=100^{\circ} \mathrm{C}$ & 26.075 & - & - & - & $\mathrm{a}$ & $\mathrm{A}$ \\
$\mathrm{S}_{2}=110^{\circ} \mathrm{C}$ & 24.844 & 2 & 0.176 & 0.243 & $\mathrm{~b}$ & $\mathrm{~B}$ \\
$\mathrm{~S}_{3}=120^{\circ} \mathrm{C}$ & 22.450 & 3 & 0.185 & 0.255 & $\mathrm{c}$ & $\mathrm{C}$ \\
$\mathrm{S}_{4}=130^{\circ} \mathrm{C}$ & 19.181 & 4 & 0.190 & 0.262 & $\mathrm{~d}$ & $\mathrm{~d}$ \\
\hline
\end{tabular}

Keterangan : Huruf yang berbeda pada kolom notasi menunjukkan pengaruh yang berbeda nyata pada taraf 5\% dan berbeda sangat nyata pada taraf $1 \%$

Dari tabel 6. Dapat dilihat bahwa $\mathrm{S}_{1}$ berbeda sangat nyata dengan $S_{2}, S_{3}$ dan $S_{4} . S_{2}$ berbeda sangat nyata dengan $S_{3}$ dan $S_{4} . S_{3}$ berbeda sangat nyata dengan $S_{4}$. Kadar Air tertinggi terdapat pada perlakuan $S_{1}$ yaitu sebesar $26.075 \%$ dan terendah terdapat pada perlakuan $\mathrm{S}_{4}$ yaitu sebesar $19.181 \%$. Untuk lebih jelasnya dapat di lihat pada gambar 5

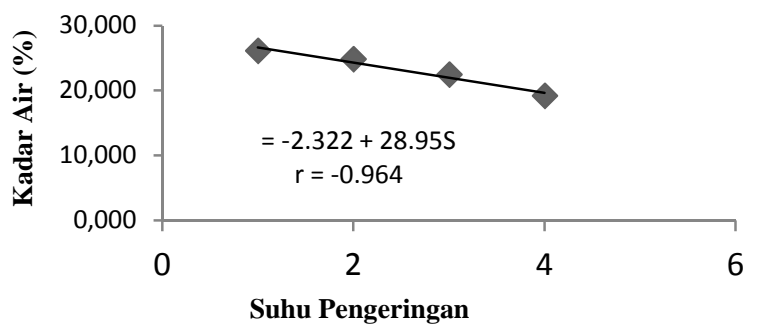

Gambar 5. Hubungan Suhu Pengeringan Terhadap Kadar Air

Dari gambar 5. Dapat dilihat bahwa pengaruh Suhu Pengeringan terhadap Kadar Air. Semakin tinggi Suhu Pengeringan maka Kadar Air pada briket semakin menurun. Kadar air briket yang tinggi dipengaruhi oleh pengeringan bahan baku yang kurang sempurna sehingga kandungan air masih banyak terdapat di dalam briket serta ukuran partikel arang yang halus sehingga lebih mudah menyerap air, yang dapat menyebabkan penyimpangan hasil kadar air briket hasil pirolisis (Usman, 2007).

\section{Pengaruh Interaksi Antara Penambahan Pati Kulit Singkong dengan Suhu Pengeringan Terhadap Kadar Air}

Dari daftar anailisis sidik ragam diketahui bahwa interaksi Penambahan Pati Kulit Singkong dan Suhu Pengeringan memberikan pengaruh berbeda sangat nyata $(\mathrm{P}<0.01)$ terhadap kadar air. Hasil uji LSR pengaruh interaksi penambahan pati kulit singkong dan suhu pengeringan terhadap kadar air kadar air briket dapat di lihat pada gambar 6 .

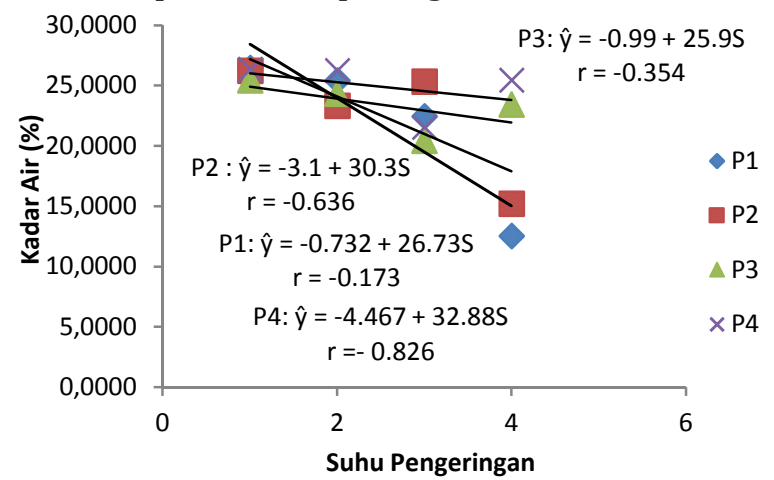

Gambar 6: Grafik Hubungan Interaksi Penambahan Pati Kulit Singkong Dan Suhu Pengeringan Terhadap Kadar Air Briket

Dari gambar 8 terlihat kadar air yang di dapat pada penelitian ini menunjukkan adanya kecenderungan semakin banyak konsentrasi perekat yang di tambahkan pada pembuatan briket pelepah kelapa sawit, maka kadar air semakin meningkat. Hal ini disebabkan adanya penambahan penambahan kadar air dari bahan perekat itu sendiri sehingga kadar air briket akan meningkat pula (Riseanggara, 2008). Faktor lain yang dapat menyebabkan rendahnya kadar air suatu briket adalah suhu pengeringan yang dilakukan maka semakin banyak air yang terbuang, sehingga kadar air briket arang semakin rendah (Sunyata, 2004).

\section{Kadar Abu \\ Pengaruh Penambahan Pati Kulit Singkong Terhadap Kadar Abu}

Dari daftar sidik ragam (Lampiran 3) dapat dilihat bahwa penambahan jumlah Pati Kulit Singkong berpengaruh berbeda sangat nyata $(P$ $<0,01)$ terhadap Kadar Abu. Tingkat perbedaan tersebut telah diuji dengan uji beda rata-rata dapat dilihat pada tabel 7 .

Tabel 7. Hasil Uji Beda Rata-Rata Penambahan Pati Kulit Singkong Terhadap Kadar Abu

\begin{tabular}{ccccccc}
\hline Perlakuan & \multirow{2}{*}{\begin{tabular}{c}
\multirow{2}{*}{ R) } \\
\cline { 3 - 7 }
\end{tabular}} & & \multicolumn{2}{c}{ LSR } & \multicolumn{2}{c}{ Notasi } \\
\cline { 3 - 7 } & & 0,05 & 0,01 & 0,05 & 0,01 \\
\hline $\mathrm{P}_{1}=5 \%$ & 19.293 & - & - & - & $\mathrm{a}$ & $\mathrm{A}$ \\
$\mathrm{P}_{2}=10 \%$ & 14.471 & 2 & 1.009 & 1.389 & $\mathrm{~b}$ & $\mathrm{~B}$ \\
$\mathrm{P}_{3}=15 \%$ & 10.675 & 3 & 1.059 & 1.460 & $\mathrm{c}$ & $\mathrm{C}$ \\
$\mathrm{P}_{4}=20 \%$ & 7.018 & 4 & 1.086 & 1.497 & $\mathrm{~d}$ & $\mathrm{D}$ \\
\hline
\end{tabular}

Keterangan: Huruf yang berbeda pada kolom notasi menunjukkan pengaruh yang berbeda nyata pada taraf 5\% dan berbeda sangat nyata pada taraf $1 \%$

Dari tabel 7. Dapat dilihat bahwa $\mathrm{P}_{1}$ berbeda sangat nyata dengan $\mathrm{P}_{2}, \mathrm{P}_{3}$, dan $\mathrm{P}_{4} . \mathrm{P}_{2}$ berbeda 
sangat nyata dengan $\mathrm{P}_{3}$ dan $\mathrm{P}_{4} . \mathrm{P}_{3}$ berbeda sangat nyata dengan $\mathrm{P}_{4}$. Kadar $\mathrm{Abu}$ tertinggi terdapat pada perlakuan $\mathrm{P}_{1}$ yaitu sebesar $19.293 \%$, dan yang terendah terdapat pada perlakuan $\mathrm{P}_{4}$ yaitu sebesar 7.018\%. Untuk lebih jelasnya dapat dilihat pada gambar 7 .

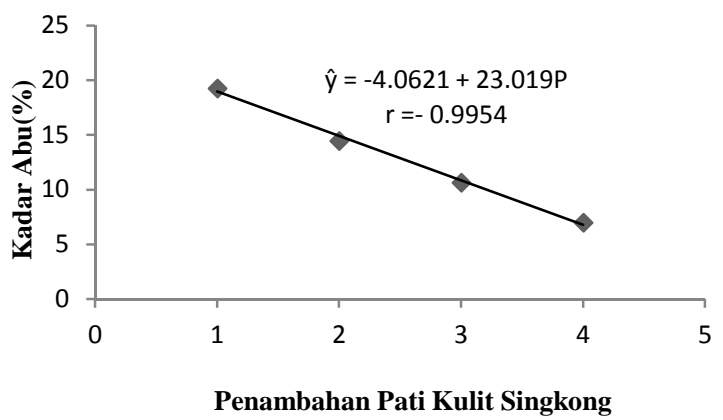

Gambar 7 : Hubungan Penambahan Pati Kulit Singkong Terhadap Kadar Abu

Dari gambar 7. Dapat dilihat bahwa penabahan jumlah pati kulit singkong terhadap kadar abu. Semakin banyak penambahan jumlah pati kulit singkong maka kadar abu semakin meningkat yaitu $19.293 \%$. Hal ini sesuai Pendapat dari Earl (1997) yang menyatakan semakin tinggi kadar abu, nilai kalor semakin rendah. Karena terlihat bahwa walaupun kadar abu dari briket yang menggunakan perekat $5 \%$ adalah yang paling tinggi, ternyata nilai kalornya justru yang paling tinggi. Salah satu unsur penyusun abu adalah silica. Pengaruhnya kurang baik terhadap nilai kalor briket arang yang dihasilkan. Kandungan abu yang tinggi dapatmenurunkan nilai kalor briket arang sehingga kualitas briket arang tersebut menurun (Masturin, 2002). Semakin banyak perekat di campurkan kedalam arang, maka kadar abu pada briket akan semakin menurun.

\section{Pengaruh Suhu Pengeringan Terhadap Kadar Abu}

Dari daftar sidik ragam (lampiran 3) dapat dilihat bahwa suhu pengeringan berpengaruh berbeda sangat nyata $(P<0,01)$ terhadap Kadar Abu. Tingkat perbedaan tersebut telah diuji dengan uji beda rata-rata dapat dilihat pada tabel 8 .

Tabel 8. Hasil Uji Beda Rata-Rata Suhu Pengeringan Terhadap Kadar Abu

\begin{tabular}{llllllc}
\hline \multirow{2}{*}{$\begin{array}{l}\text { Perlakuan } \\
(\mathrm{S})\end{array}$} & \multirow{2}{*}{ Rataan } & \multirow{2}{*}{ Jarak } & \multicolumn{2}{c}{ LSR } & \multicolumn{2}{c}{ Notasi } \\
\cline { 3 - 7 } & 0,05 & 0,01 & 0,05 & 0,01 \\
\hline $\mathrm{S}_{1}=100^{\circ} \mathrm{C}$ & 14.688 & - & - & - & $\mathrm{a}$ & $\mathrm{A}$ \\
$\mathrm{S}_{2}=110^{\circ} \mathrm{C}$ & 13.123 & 2 & 1.009 & 1.389 & $\mathrm{~b}$ & $\mathrm{~B}$ \\
$\mathrm{~S}_{3}=120^{\circ} \mathrm{C}$ & 12.144 & 3 & 1.059 & 1.460 & $\mathrm{bc}$ & $\mathrm{BC}$ \\
$\mathrm{S}_{4}=130^{\circ} \mathrm{C}$ & 11.503 & 4 & 1.086 & 1.497 & $\mathrm{~cd}$ & $\mathrm{Cd}$ \\
\hline $\begin{array}{l}\text { Keterangan: Huruf } \\
\text { menunjukkan pengaruh yang berbeda }\end{array}$ & pada & kolom & notasi \\
man berbeda sangat nyata pada taraf 1\% & &
\end{tabular}

Dari Tabel 8. Dapat dilihat bahwa $\mathrm{S}_{1}$ berbeda sangat nyata dengan $S_{2}, S_{3}$ dan $S_{4} . S_{2}$ berbeda tidak nyata dengan $S_{3}$ dan $S_{4} . S_{3}$ berbeda tidak nyata dengan $S_{4}$. Kadar Abu tertinggi terdapat pada perlakuan $S_{1}$ yaitu sebesar $14.688 \%$ dan terendah terdapat pada perlakuan $\mathrm{S}_{4}$ yaitu sebesar $11.503 \%$. Untuk lebih jelasnya dapat di lihat pada gambar 8 .

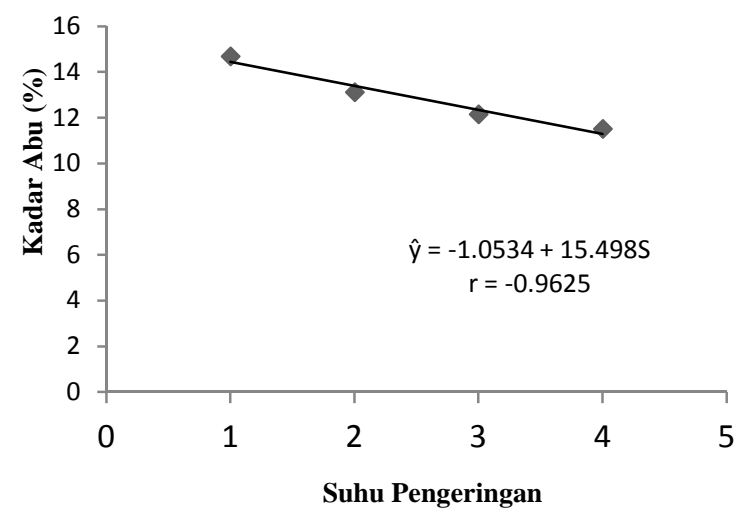

Gambar 8: Hubungan Suhu Pengeringan Terhadap Kadar Abu

Gambar 8. Dapat dilihat bahwa pengaruh suhu pengeringan terhadap kadar abu, semakin tinggi suhu pengeringan maka kadar abu pada briket semakin menurun. Menurut Hendra dan Darmawan (2000), salah satu unsur kadar abu adalah silikat dan pengaruhnya kurang baik terhadap nilai kalor yang dihasilkan. Semakin rendah kadar abu maka semakin baik kualitas briket yang dihasilkan. Menurut Jamilatul (2011), abu yang terkandung dalam bahan bakar padat ada mineral yang tidak dapat terbakar tertinggal setelah proses pembakaran dan reaksi-reaksi menyertainya selesai. Dengan semakin tinggi suhu pengeringan maka kadar abu pada arang semakin rendah, abu akan menurunkan mutu bahan bakar padat karena dapat menurunkan nilai kalor. 
Pengaruh Interaksi Antara Penambahan Pati Kulit Singkong dengan Suhu Pengeringan Terhadap Kadar Abu

Dari daftar anailisis sidik ragam (lampiran 3) diketahui bahwa interaksi Penambahan Pati Kulit Singkong dan Suhu Pengeringan memberikan pengaruh berbeda tidak nyata $(\mathrm{P}>$ 0.05) terhadap Kadar Abu sehingga pengujian selanjutnya tidak dilakukan.

\section{KESIMPULAN}

Dari hasil penelitian dan pembahasan pengaruh penambahan jumlah pati kulit singkong dan suhu pengeringan terhadap mutu briket dapat di simpulkan sebagai berikut :

1. Penambahan jumlah pati kulit singkong memberi pengaruh yang berbeda sangat nyata terhadap nilai kalor, kadar air dan kadar abu.

2. Suhu pengeringan memberikan pengaruh yang berbeda sangat nyata terhadap nilai kalor, kadar air dan kadar abu

3. Interaksi perlakuan penambahan pati kulit singkong dengan suhu pengeringan memberikan pengaruh yang berbeda sangat nyata terhadap Nilai Kalor dan Kadar Air sedangkan kadar abu memberikan pengaruh berbeda tidak nyata.

\section{DAFTAR PUSTAKA}

Desi Ardilla, Bahrin, M.Taufik, 2007. Pembuatan Karbon Aktif Dari Cangkang Kelapa Sawit. Agrium, 14(2):10-13

Desi Ardilla, Bahrin, M.Taufik , 2011. Optimasi Pada PenambahanZat Aditif Terhadap Nilai Kalor Briket Cangkang Kelapa Sawit. Agrium, 16(3):116-123

Earl, D.E, 1997. A Report On Corcoal, Andre Meyer Research Fellow. Fao. Rome

Gandhi, A. 2010. Pengaruh variasi jumlah campuran perekat terhadap karakteristik briket arang tongkol jagung. Profasional. 8(1):1-11

Hartoyo, J Dan Roliandi, H. 1978. Percobaan Pembuatan Briket Arang Dari Lima Jenis Kayu. Indonesia. Laporan Penelitian Lembaga Hasil Hutan. Bogor.

Hendra Dan Darmawan, 2000. Pengaruh Bahan Baku, Jenis Perekat Dan Tekanan Kempa
Terhadap Kualitas Briket Arang. Bogor: Pusat Penelitian Dan Pengembangan Hasil Hutan.

Jamilatul S, 2011. Kualitas Sifat-Sifat Penyala Dari Pembakaran Briket Tempurung Kelapa, Briket Serbuk Gergaji Kayu Jati, Briket Sekam Padi Dan Batu Bara, Di Dalam Prosiding Seminar Nasional Teknik Kimia"kejuangan" 2011.

Manik Fs. 2010. Pemanfaatan Spent Bleaching Earth Dari Proses Pemucatan Cpo Sebagai Bahan Baku Briket. Bogor: Institut Pertanian Bogor.

Masturin, A. 2002. Sifat Fisik Kimia Dan Briket Arang Dari Campuran Arang Limbah Gergaji Kayu [Skripsi]. Bogor. Fakultas Kehutanan. Institute Pertanian Bogor.

Pancapalaga, A. 2008. Sifat Fisik Dan Kimia Briket Arang Dari Campuran Arang Limbah Pertanian Sebagai Bahan Bakar Alternatif.

Purnama, R. R., A. Chumaidi, And A. Saleh. 2012. Pemanfaatan Limbah Cair Cpo Sebagai Perekat Pada Pembuatan Briket Dari Arang Tandan Kosong Kelapa Sawit. 18:45.

Riseanggara Rr. 2008. Optimasi Kadar Perekat Pada Briket Limbah Biomassa. Bogor : Perpustakaan Institut Pertanian Bogor.

Sanotsa, Misiaini R., Dan Swara Pratiwi A, 2013. Studi Variasi Komposisi Bahan Penyusun Briket Arang Dari Kotoran Sapi Dan Limbah Pertanian.

Sunyata, A. 2004, Pengaruh Kerapatan Dan Suhu Pirolisa Terhadap Kualitas Briket Arang Serbuk Kayu Sengon, Fakultas Kehutanan Institut Pertanian Yogyakarta

Tobing, Febrina Setyawati Dan Brades, A. Chandra. 2007. Pembuatan Briket Arang Dari Enceng Gondok (Eichornia Crasipess Solm) Dengan Sagu Sebagai Pengikat. Jurusan Teknik Kimia. Indralaya: Unsri.

Triono, A. 2006. Karakteristik Briket Arang Dari Campuran Serbuk Gergaji Kayu Afrika (Maesopsis Eminii Engl) Dan Sengon (Paraserianthes Falcataria L. Nielsen) 
Dengan Penambahan Tempurung Kelapa (Cocos Nucifera L). Bogor: Departemen Hasil Hutan Fakultas Kehutanan Ipb

Usman, M.Natsir. 2007. Mutu Briket Arang Kulit Buah Kakao Dengan Menggunakan Kanji Sebagai Perekat. 3:57. 